Gut, 1973, 14, 183-186

\title{
Volatile fatty acids in the faeces of patients in 'germ-free' isolation
}

\author{
D. GOMPERTZ, A. P. BROOKS, H. GAYA, AND A. S. D. SPIERS \\ From the MRC Intestinal Malabsorption Research Group, Department of Medicine, Department of \\ Bacteriology and MRC Leukaemia Unit, Royal Postgraduate Medical School, London
}

SUMMARY Faecal volatile fatty acids represent the end products of the metabolism of the anaerobic flora of the large bowel. The excretion of these volatile acids has been investigated in five leukaemic patients maintained in plastic 'germ-free' isolators. Under 'isolator' conditions there is a pronounced fall in volatile fatty acid excretion. The possibility that the measurement of these acids may be used to monitor anaerobic overgrowth and recolonization in these patients is discussed.

The excretion of volatile fatty acids in the faeces of normal subjects has been investigated in many clinical conditions (see Rubinstein, Howard, and Wrong, 1969). These acids are produced by, and characterize, the fermentation reactions of intestinal anaerobic organisms. Measurements of faecal volatile fatty acids have not so far been found to give clinically useful data. However, we have recently demonstrated that the concentration of volatile fatty acids in jejunal aspirates can be used to indicate an anaerobic overgrowth of the small bowel (Chernov, Doe, and Gompertz, 1972).

A series of patients undergoing a programme of cytotoxic therapy for leukaemia have been nursed in plastic isolators under as near 'germ-free' conditions as possible (Trexler and Reynolds, 1957; Gaya, 1972). The bacteriological techniques required to investigate an anaerobic overgrowth in the large bowel are complex, and it seemed that volatile fatty acid excretion in these patients might be a useful index of the bacterial colonization of the large bowel. The faecal excretion of volatile fatty acids by five patients nursed in plastic isolators has been compared with that of a group of normal controls.

Received for publication 30 November 1972.

\section{Patients}

Five leukaemic patients were treated with intestinal 'sterilizing' regimens (Table I) (Gaya, 1972). The techniques for skin and nasopharyngeal sterilization as part of the general preparation for entry into the germ-free isolators and details of the plastic isolators and nursing techniques are presented separately (Gaya, 1972). Faeces were removed from the isolators in sterile bed-pan liners immediately they had been passed and were transferred to plastic bottles precooled at $-25^{\circ}$. All patients were receiving an alternating sequence of cytotoxic drugs (Spiers, 1972). Two of these patients, A.A. and I.A., received codeine phosphate $(90 \mathrm{mg} /$ day) to control episodes of diarrhoea.

\section{Methods}

Faecal samples were collected daily and stored at $-25^{\circ}$ until analysis. All patients except I.A. produced samples at approximately 24-hour intervals. Faecal samples from eight normal controls were also collected and frozen immediately over solid $\mathrm{CO}_{2}$. The controls were selected from staff members who usually passed one stool every 24 hours.

\begin{tabular}{lllll}
\hline Patient & Sex & Age & Diagnosis & Antibiotics \\
\hline A.A. & F & 26 & $\begin{array}{l}\text { Chronic granulocytic leukaemia in acute } \\
\text { transformation }\end{array}$ & Gentamicin, vancomycin, nystatin \\
A.P. & F & 30 & $\begin{array}{l}\text { Myeloblastic leukaemia } \\
\text { Acute myelomonocytic leukaemia }\end{array}$ \\
I.A. & M & 23 & Acute myelomonocytic leukaemia & Vancomycin, colistin, nystatin \\
L.T. & F & 21 & Vancomycin, colistin, nystatin \\
C.B. & M & 54 & Myeloblastic leukaemia & Vancomycin, colistin, nystatin \\
\end{tabular}


The samples were collected in 2 litre polythene containers: $30 \mathrm{ml}$ of $25 \%$ phosphoric acid and 500 $\mathrm{ml}$ of distilled water were added to the frozen faeces and homogenization was started in the plastic bottle before the faeces had thawed, using a Silversen laboratory mixer-emulsifier. The homogenate was maintained at $p \mathrm{H} \mathrm{1-2}$ and the volume was made up to 1 litre while the homogenization was continuing. These acid conditions ensured that no bacterial fermentation could occur between the collection of the faeces into the precooled containers and the final analysis.

The acidified faecal homogenates were sampled with plastic syringes and $20 \mathrm{ml}$ aliquots transferred to universal containers. These were centrifuged and $10 \mathrm{ml}$ of the supernatant was used for steam distillation and gas chromatography (Chernov, Doe, and Gompertz, 1972). Distilled water was homogenized with acid in an empty faecal collection bottle in parallel with each batch of faeces analysed. Steam distillation and gas chromatography of this sample was performed to give a 'blank' for the method which was routinely subtracted from the patients' results.

\section{Results}

The concentrations and the percentage distribution of the volatile fatty acids in the faeces from the eight normal controls are presented in Table II. These results correspond closely to those described by previous authors (Rubinstein et al, 1969), acetate, propionate, and butyrate accounting for $90 \%$ of the steam-volatile acids in faeces. Preliminary experiments showed large differences in volatile acid excretion between patients in 'germ-free' isolators and controls. The chromatograms presented in Fig. 1 were performed at the same amplification to illustrate these differences.

The results for acetate excretion are given in Table III. The mean acetate excretion per 24 hours is presented for the eight controls. It is not obvious whether the values for acetate excretion in normal persons are normally or logarithmically distributed, and so the range of values found, rather than a standard deviation, is given in this table. The first patient (A.A.) was followed for nine and a half weeks and six daily collections were usually obtained

\begin{tabular}{|c|c|c|c|c|c|c|}
\hline Excretion & Acetate & Propionate & Butyrate & Valerate & Isovalerate & Isobutyrate \\
\hline $\begin{array}{l}\mu \text { Moles/24 hours } \\
\text { Percentage distribution }\end{array}$ & $\begin{array}{r}5090 \\
54\end{array}$ & $\begin{array}{r}1940 \\
21\end{array}$ & $\begin{array}{r}1810 \\
19\end{array}$ & $\begin{array}{r}225 \\
2 \cdot 4\end{array}$ & $\begin{array}{r}220 \\
2 \cdot 3\end{array}$ & $\begin{array}{l}155 \\
1.6\end{array}$ \\
\hline
\end{tabular}

Table II Mean volatile fatty acid excretion in eight normal controls
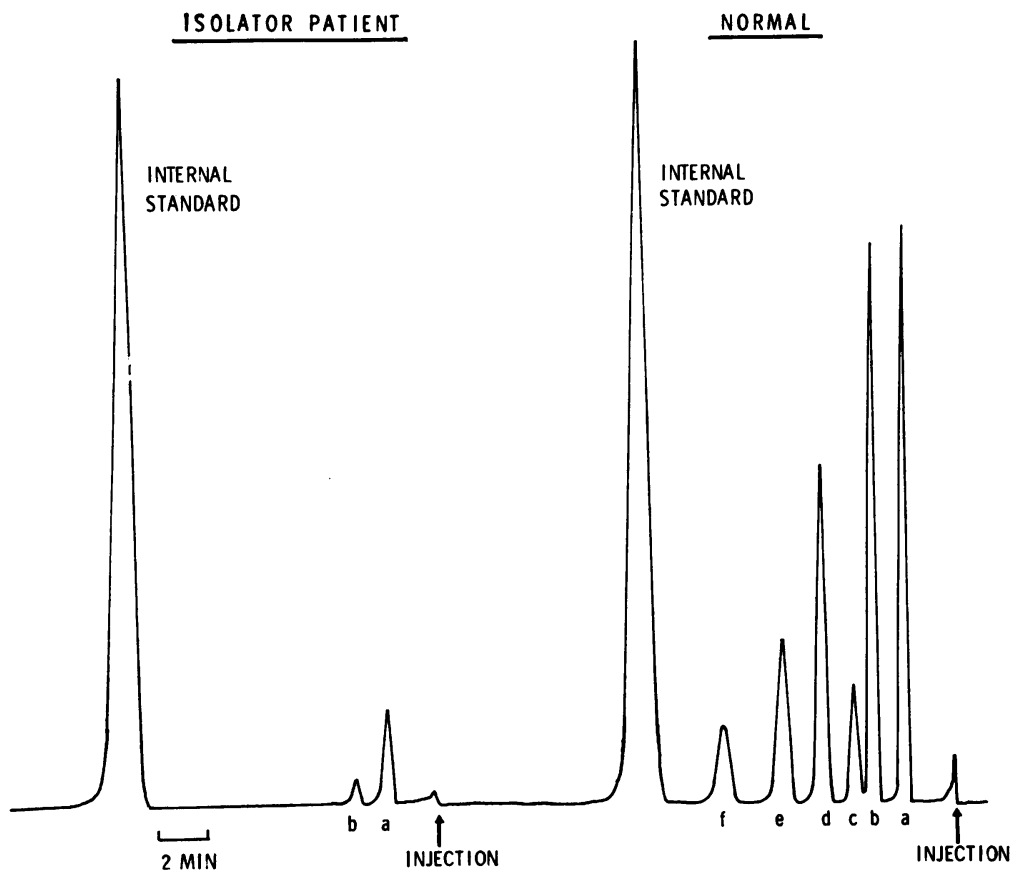

Fig. Gas chromatographic tracings of volatile fatty acids from an 'isolator' patient and a normal control.

The volatile acids are designated: a acetic, $\mathrm{b}$, propionic; c, isobutyric; $\mathrm{d}$, butyric; $\mathrm{e}$, isovaleric; and $\mathrm{f}$, valeric acids.

The internal standard is 3-methylvaleric acid. 


\begin{tabular}{llrrl}
\hline Normals & \multicolumn{3}{l}{ Patients } & \\
\cline { 2 - 5 } & & Mean & Range & $\begin{array}{l}\text { No. of } \\
\text { Samples }\end{array}$ \\
\hline Mean $=5090$ & A.A. & 107 & $20-421$ & $(55)$ \\
Range $=1000-17560$ & A.P. & 74 & $13-279$ & $(11)$ \\
& I.A. & 329 & $101-654$ & $(5)$ \\
$\mathrm{n}=8$ normal persons & L.T. & 42 & $9-105$ & $(3)$ \\
& C.B. & 65 & $33-84$ & $(3)$ \\
\hline
\end{tabular}

Table III Excretion of acetate in normals and patients in isolators $^{1}$

${ }^{1}$ Results expressed as $\mu$ moles acetic acid/24 hours.

per week. The seventh collection was discarded because it was not frozen immediately, as samples were required by other laboratories investigating these patients. The mean acetate excretion in this patient, $107 \mu$ moles $/ 24$ hours, was below the lower limit for our normal subjects, and even the maximum, and unusually high figure of $421 \mu$ moles/24 hours, was considerably lower than the normal range. During this period of observation there was no bacteriological evidence of anaerobic colonization (Gaya, 1972). The results in A.P., L.T., and C.B. are similar, the mean acetate excretion being less than $100 \mu$ moles/24 hours for each patient. I.A., however, produced considerably more acetate in each sample but differed from the other patients in only producing one stool every three or four days. The results of each of the faecal samples from this patient are presented directly without taking the average excretion over the period elapsing from the collection of the previous sample.

Two patients were discharged from the 'isolators' and sent home immediately. A.A. was allowed to recolonize herself spontaneously at home, away from possible colonization by hospital organisms, and A.P. was colonized with a known culture of mixed intestinal anaerobes (from Dr D. Van der Waaij) and samples were collected a few days after colonization had been performed. Both patients' faecal acetate excretion rose to within the control range (Table IV). With I.A., we were able to obtain two samples before antibiotic treatment was started and these were also normal (Table IV).

\begin{tabular}{llll}
\hline Patient & \multicolumn{1}{l}{ Isolation } \\
\cline { 2 - 4 } & Before & $\begin{array}{c}\text { During (mean } \\
\text { values) }\end{array}$ & After \\
\hline A.A. & - & 107 (55 days) & 1620 (3 days) \\
A.P. & - & 74 (11 days) & 6400 (3 days) \\
I.A. & $5700(2$ days) & 329 (5 days) & - \\
\hline
\end{tabular}

Table IV Comparison of acetate excretion inside and outside the 'germ-free' isolators in three patients ${ }^{1}$

${ }^{1}$ Results expressed as $\mu$ moles acetic acid/24 hours.
Propionate excretion was measured in all the control samples and in several of the samples from each 'isolator' patient (Table V). The differences in propionate excretion between normals and 'isolator' patients were even greater than the differences in peak heights seen in the chromatograms in Fig. 1; this is because significant amounts of propionate occur in the 'blank' samples and the total propionate excretion in the 'isolator' patients frequently did not exceed the 'blank' propionate values found in control homogenizations. Propionate was recorded as absent on these occasions.

\begin{tabular}{llll}
\hline Normals & \multicolumn{2}{l}{ Patients } & \\
\cline { 2 - 4 } & & Range & No. of Samples \\
\hline Mean $=1940$ & A.A. & $0-0 \cdot 8$ & $(19)$ \\
Range $=350-6420$ & A.P. & $0-0 \cdot 3$ & $(3)$ \\
& I.A. & $1-25$ & $(5)$ \\
$\mathrm{n}=8$ normal persons L.T. & $0 \cdot 1-1 \cdot 2$ & $(3)$ \\
& C.B. & $0-4 \cdot 6$ & $(3)$ \\
\hline
\end{tabular}

Table $\mathrm{V}$ Excretion of propionate in normals and patients in isolators 1

${ }^{1}$ Results expressed as $\mu$ moles propionic acid/24 hours.

\section{Discussion}

The bacterial ecology of the large bowel is complex and investigation of the interaction of various forms of the anaerobic flora has been hampered by technical difficulties in culturing, identifying, and quantifying precisely the various anaerobes (Drasar, 1967; Moore, Cato, and Holderman, 1969; Gorbach, 1971). On the other hand, germ-free animals colonized with known strains of anaerobes have helped considerably in investigating these bacterial interrelationships (Luckey, 1970). The development of germ-free isolators for animal studies has led to their use for patients undergoing intensive cytotoxic therapy for leukaemia. The bacteriological study of these 'germfree' patients is time-consuming due to the problems inherent in the use of anaerobic techniques. We have already demonstrated that the measurement of volatile fatty acids in the stagnant-loop syndrome may provide a useful marker for anaerobic colonization of the small bowel (Chernov et al, 1972). The purpose of the present study was to investigate the excretion pattern of volatile acids in the faeces of patients in 'isolators' in order to see whether the levels of these acids were altered sufficiently for their measurement to be a useful indicator of the presence or absence of an anaerobic flora in the large bowel.

It is evident from Fig. 1 and Table III that there is an entirely different pattern of volatile fatty acid excretion from normal persons and from 'isolator' 
patients. Butyric acid and the minor components cannot be seen in this sample from an isolator patient at this amplification. During this study, however, the samples from the 'isolator' patients were usually analysed at high amplification and trace amounts of these acids were seen. When the concentrations of these minor components in the blanks and in the faecal samples from the isolator patients had been established, it was apparent that only acetate and propionate were present in measurable amounts in these five patients. This is in keeping with previous studies of the effects of antibiotics in faecal metabolites in normal persons (Asatoor, Chamberlain, Emmerson, Johnson, Levi, and Milne, 1967).

The concentration of acetic acid in the eight normal controls appears to be distributed in a nonlinear manner. The total number of organisms per gram of faeces is usually expressed on a logarithmic scale and thus the results of their metabolic activity should not necessarily be normally distributed. This makes it difficult to express the acetate results, as the accumulation of the large number of normal samples required to establish the mode of distribution was outside the range of this investigation. There is no doubt, however, that the acetate excretion in the 'isolator' patients was very much less than in the normals. In patient A.A. 50 of the 55 daily samples were less than $250 \mu$ moles/ 24 hours. Similar results were obtained from the three patients, A.P., L.T., and C.B. I.A. produced faeces at intervals of several days. These results were not averaged over the period between samples because it was not known whether retention of faeces is associated with an increased volatile acid production (longer incubation time) or with a decreased excretion (due to limitation of substrate and/or absorption of acids by the large bowel) (Dawson, Holdsworth, and Webb, 1964).

Although the maximum excretion of acetate in one of the isolator patients (654 $\mu$ moles/24 hours) approached the lower limit of our normal range, ie, $1000 \mu$ moles/24 hours, this sample could be easily distinguished from normal on the basis of the low propionate output ( $23 \mu$ moles $/ 24$ hours). Propionate excretion appears to be in some ways an even more reliable indicator of the absence of anaerobic colonization in the large bowel, but the output of propionate by various anaerobes varies greatly. The proportion of propionobacteria in any flora will greatly affect the acetate/propionate ratio. It appears that acetate and propionate levels together may be a better indicator of anaerobic overgrowth in the 'germ-free' large bowel.

The comparison of acetate excretion in two patients during and after isolation and in a third before and during isolation (Table IV) shows that these three patients had normal acetate excretion outside the 'germ-free' isolator, demonstrating that the observed changes were not secondary to these patients' leukaemic states or the cytotoxic treatment. Patient A.A. was allowed to colonize herself at home and the first sample analysed, 48 hours after antibiotics were stopped, just exceeded 1000 $\mu$ moles/24 hours. Patient A.P., by contrast, was recolonized both orally and by retention enema using a mixture of intestinal anaerobes. This was followed, the next day, by a massive acetate and propionate excretion (19 400 and $4700 \mu$ moles/24 hours respectively). This may be similar to the 'overshoot' in the urinary output of indolylacetic and p-hydroxyphenylacetic acids reported by Asatoor et al (1967) after the end of neomycin administration.

Analysis of faecal volatile fatty acids by steam distillation and gas chromatography is a relatively simple technique, and is faster to perform than quantitative anaerobic bacteriology. In the patient in 'germ-free' isolation, gas chromatography might be a useful method of monitoring accidental anaerobic overgrowth. The two tracings in Fig. 1 show that quantitation of each individual volatile acid is probably unnecessary and that a change in pattern on colonization is easy to recognize.

We thank Professor C. C. Booth for advice and encouragement throughout this investigation. The cooperation of the nursing staff of the Anaemia Unit is gratefully acknowledged.

\section{References}

Asatoor, A. M., Chamberlain, M. J., Emmerson, B. T., Johnson, J. R. Levi, A. J., and Milne, M. D. (1967). Metabolic effects of oral neomycin. Clin. Sci., 33, 111-124.

Chernov, A. J., Doe, W. F., and Gompertz, D. (1972). Intrajejunal volatile fatty acids in the stagnant loop syndrome. Gut, 13 , 103-106.

Dawson, A. M., Holdsworth, C. D., and Webb, J. (1964). Absorption of short chain fatty acids in man. Proc. Soc. exp. Biol. (N.Y.), 117, 97-100.

Drasar, B. S. (1967). Cultivation of anaerobic intestinal bacteria. J. Path. Bact., 94, 417-427.

Gaya, H. (1972). Patient isolators. Brit. Hosp. J. soc. Serv. Rev., 82 (Suppl.) 15.

Gorbach, S. L. (1971). Intestinal microflora. Gastroenterology, 60, $1110-1129$.

Luckey, T. D. (1970). Gnotobiology is ecology, Amer. J. clin. Nutr., 23, 1533-1540.

Moore, W. E. C., Cato, E. P., and Holdeman, L. V. (1969). Anaerobic bacteria of the gastrointestinal flora and their occurrence in clinical infections. J. infect. Dis., 119, 641-649.

Rubinstein, R., Howard, A. V., and Wrong, O. M. (1969). In vivo dialysis of faeces as a method of stool analysis. IV. The organic anion component. Clin. Sci., 37, 549-564.

Spiers, A. S. D. (1972). Chemotherapy of acute leukaemia. Clin. Haemat., 1, 127-164.

Trexler, P. C., and Reynolds, L. I. (1957). Flexible film apparatus for the rearing and use of germfree animals. Appl. Microbiol., 5, 406-412. 